\title{
Clinical use of parnaparin in major and minor orthopedic sugery: a review
}

\author{
Stefano Bugamelli' \\ Elena Zangheri \\ Milena Montebugnoli' \\ Lucia Guerra ${ }^{3}$ \\ 'Servizio di Anestesia e Rianimazione, \\ IRCCS Istituti Ortopedici Rizzoli, \\ Bologna, Italy; ${ }^{2}$ Unità Operativa \\ di Anestesia e Terapia Intensiva \\ Postoperatoria Prof. G. Di Nino, \\ Policlinico Sant'Orsola Malpighi, \\ Bologna, Italy; ${ }^{3}$ Medical Department \\ Alfa Wassermann, Bologna, Italy
}

\begin{abstract}
Patients undergoing arthroplasty or other orthopedic surgery show a high risk of venous thromboembolism (VTE), involving mortality, morbidity, and social costs; however, the risk for VTE in minor orthopedic surgery should not be underestimated and antithrombotic prophylaxis may be required. According to the literature, low-molecular-weight heparins (LMWHs) are more effective in preventing VTE than unfractionated heparins (UFHs) or vitamin $\mathrm{K}$ antagonists, and have a lower hemorrhagic risk. By comparing different prophylactic regimens, it has been shown that starting the prophylaxis near the time of the operation is the most critical point for efficacy, whether or not the first dose is administered pre- or post-operatively. Moreover, most thromboembolic complications are observed after discharge and, therefore, many clinicians advocate continuing prophylaxis for longer times (6-8 weeks) in order to further reduce the rate for VTE. The literature on parnaparin, a new LMWH, in VTE prophylaxis was reviewed. Parnaparin is equally effective as UFH, but it offers the advantages of a once-daily administration and improved tolerability, thus allowing the home management of patients with no need for laboratory coagulation tests.
\end{abstract}

Keywords: orthopedic surgery, low molecular weight heparins, antithromboembolic prophylaxis, parnaparin

\section{Prophylaxis of venous thromboembolism}

Patients undergoing elective arthroplasty (hip or knee) or other major orthopedic surgery are at high risk of developing venous thromboembolism (VTE), which represents a dangerous event in terms of mortality and morbidity with high social impact and costs.

Randomized clinical trials (RCT) estimate that, in absence of a thromboprophylaxis, the incidence of venographically proven VTE ranges from $45 \%$ to $57 \%$ after total hip replacement (THR) surgery, 36\% to 60\% after hip fracture surgery (HFS), and $40 \%$ to $84 \%$ after total knee replacement (TKR) surgery (Geerts et al 2001; Geerts et al 2004).

Although low-dose unfractionated heparin (UFH) (Collins et al 1988) and aspirin (Antiplatelet Trialists' Collaboration 1994) have been reported more effective than no prophylaxis in patients undergoing THR, these agents have been abandoned today in favor of low-molecular-weight heparins (LMWHs), vitamin K antagonists, and synthetic derivatives of factor Xa inhibitor, such as fondaparinux.

In fact, several studies (Chiapuzzo et al 1988; Mascali et al 1988; Planes et al 1988; Pini et al 1989; German Hip Arthroplasty Trial Group 1992; Colwell et al 1994; Haas et al 2006) and meta-analyses (Nurmohamed et al 1992; Freedman et al 2000; Koch et al 2001) have confirmed that LMWHs are more effective than low-dose or adjusted-dose UFH with a relative risk reduction of $25 \%-50 \%$. Moreover, LMWH are as effective as vitamin $\mathrm{K}$ antagonists in the TVE prevention, but they have a lower hemorrhagic risk (Imperiale and Speroff 1994; Palmer et al 1997; Fitzgerald et al 2001; 
Samama et al 2002; Bandiera et al 2003; Haas et al 2006; Prejbeanu et al 2007).

While the phophylactic efficacy of LMWH is today unquestioned, the treatment schedule (when to begin, how many times a day, and for how long) is a still debated point.

The standard protocols in North America recommend the administration of a first LMWH dose between 12 and 24 hours after surgery, whereas in Europe the prophylaxis is often begun pre-operatively (10-12 hours before surgery) (Strebel et al 2002). Several authors have compared different prophylactic regimens in order to ascertain whether the first dose is more effective if given pre- or post-operatively. It has been shown that starting the prophylaxis near the time of the operation is the most critical point, whether or not the first dose is administered pre- or post-operatively (Laguardia and Caroli 1992; Strebel et al 2002; Bandiera et al 2003; Raskob and Hirsh 2003). A review of RCTs has shown a reduction of $40 \%-50 \%$ in the DVT rate in THR patients when the prophylaxis was begun between 2 hours before and 8 hours after surgery, although the pre-operative administration of heparin seemed to involve a higher hemorrhagic risk (Hull et al 2001). The risk can be reduced, however, by giving an early post-operative (6-8 hours) low dose of heparin, and by increasing the doses of heparin in the following 24 hours or later, according to the course of post-operative bleeding (Hull et al 2000; Geerts et al 2004).

On the other hand, the risk for TVE is not confined to the immediate post-operative period. According to literature, most of symptomatic TVE complications (12\%-35\%) occur after discharge; thus, several authors suggest that the prophylactic treatment should be continued for longer times (6-8 weeks) whenever risk factors are present, and be stopped only when full weight on the treated limb is resumed. It has been reported that continuation of prophylaxis for at least 2 weeks may further reduce the TVE risk by an additional 50\% (White et al 1998; Samama et al 2002; Geerts et al 2004; Goldhaber 2004; Verhaeghe 2005; Arcelus et al 2006; Prejabeanu et al 2007).

Finally, the risk for TVE in minor orthopedic surgery should not be underestimated even if an antithromboembolic prophylaxis is rarely used in these patients. The presence of concomitant risk factors for thromboembolism, as well as the frequent use of a tourniquet with subsequent revascularization in performing these operations, may explain the high rate of TVE complications in this "minor" surgery. Thus, appropriately long prophylaxis with LMWH is also indicated in these patients (Obermosterer et al 1999; Michot et al 2002; Montebugnoli et al 2007).

\section{Low-molecular-weight heparins}

LMWHs are extracted from UFH of animal origin with a molecular weight (MW) ranging between 4,000 and 30,000 Da. The activity of LMWHs is mediated by their binding to antithrombin III (AT III); however, because of fragmentation, the coagulation factors IIa and Xa are affected differently by AT III and, therefore, the antithrombotic activity is separated by the anticoagulant effect because of a larger anti-Xa activity compared with anti-IIa activity.

The structural changes in LMWHs modify the pharmacokinetics compared with UFH: the absorption after subcutaneous (sc) administration is almost complete, predictable, and reliable. The smaller molecules have a lower binding to plasma and tissue proteins and, consequently, a higher antithrombotic activity is available in the plasma; moreover, LMWHs undergo reduced liver metabolism and have an increased renal elimination. The plasma half-life of LMWHs is therefore longer than that of UFH, although to varying degrees among different molecules, thus allowing for a single daily administration.

The anti-Xa/anti-IIa activity rate expresses the relationship between the doses producing the desired antithrombotic activity, and those producing the undesired anticoagulant effects. This way of expressing the activity of the LMWH has a clinical meaning during DVT prophylaxis, the main objective of prophylaxis being to inhibit the formation and growth of fibrin thrombus at the site of DVT without affecting the systemic coagulation. It is generally recognized that the greater is the fractioning of the AT III-binding chain, the shorter and more homogeneous the synthetic molecule, and the more selective the inhibitory activity on factor Xa compared with factor IIa.

\section{Parnaparin}

Our aim was to review the available clinical data on parnaparin, a LMWH that is effective and generally well tolerated in the prevention of VTE, as well as in the treatment of arterial and venous diseases (McKeage and Keating 2008). The data source was PubMed, which was searched for "parnaparin" or "Fluxum", returning 4 reviews and 25 experimental works; no restriction on language and time was applied. Moreover, published reports not listed in PubMed were provided by Alfa Wassermann S.p.A. (Bologna, Italy). Dosages of parnaparin reported in this review $(3,200,6,400$ and 12,800 IUaXa) were calculated using the chromogenic method from the European Pharmacopoea Standard of LMWH. These units are equivalent to those mentioned in clinical papers from the 1980 s through to the mid 1990 s 
(7,500, 15,000, and 30,000 aXaU), which were calculated using the chromogenic method from the 4th International Standard of Unfractionated Heparin.

\section{Pharmacology and pharmacokinetics}

Parnaparin is a LMWH obtained with an original and patented procedure of fragmentation, which guarantees the homogeneity of fragments in terms of molecular weifht; thus, all the fragments have the right length to optimize the dissociation between the antithrombotic and anticoagulant activities (anti-Xa/anti-IIa ratio $>4$ ).

The most interesting characteristics of parnaparin are its speed of action after sc administration $\left(\mathrm{T}_{\max } \approx 3\right.$ hours) and its plasma half-life (about 6 hours), which are ideal for a single daily administration (Summary of Product Characteristics approved by Regulatory Authorities); therefore, parnaparin provides a rapid antithrombotic protection in urgent situations, and it has a minimal risk for drug accumulation and consequent hemorrhagic risk (Table 1).

In principle, the predictable and constant pharmacokinetics of parnaparin makes its use much easier and simpler in day-by-day clinical practice; moreover, like other LMWHs, the low influence of parnaparin on coagulation means that repeated lab tests are not needed monitor coagulation times. The consequent practical advantage is a simpler management of post-operative DVT prophylaxis at home.

Experimental observations show the ability of parnaparin to prevent in vitro the activation of platelets and leukocytes, and to inhibit the formation of leukocyteplatelet aggregates (Maugeri et al 2005; Ludwig et al 2006; Maugeri et al 2007).

The neutralization of parnaparin by protamine chloride has been studied in vitro on coagulation tests (APTT, anti-Xa activity). The activity of parnaparin on APTT has been completely neutralized by protamine with a parnaparin/protamine ratio of $\mathrm{IUaXa} / 20 \mu \mathrm{g}$, whereas anti-Xa activity has been

Table I Pharmacokinetic parameters of unfractionated heparins and low-molecular-weight heparins

\begin{tabular}{lllll}
\hline & Absorption & Tmax & t'1/2 & $\begin{array}{l}\text { Anti-Xal } \\
\text { Anti-Ila }\end{array}$ \\
\hline Sodium UFH & $15 \%-30 \%$ & 3 hours & I hour & I \\
Tinzaparin & $90 \%$ & $4-6$ hours & 1.5 hours & 1.5 \\
Dalteparin & $90 \%$ & $3-4$ hours & 4 hours & 2.6 \\
Reviparin & $95 \%$ & $3-4$ hours & 3 hours & 3.5 \\
Enoxaparin & $100 \%$ & 3 hours & 4.4 hours & 4 \\
Nadroparin & $98 \%$ & $4-6$ hours & $8-10$ hours & $>4$ \\
Parnaparin & $>90 \%$ & 3 hours & 6 hours & $>4$ \\
\hline
\end{tabular}

partially but substantially neutralized by protamine (Milani and Palazzini 1990).

\section{Parnaparin in major orthopedic surgery}

Clinical evidence for the effectiveness of LMWH and, especially, of parnaparin, in the prevention of DVT in patients undergoing major orthopedic surgery for arthroplasty and trauma has been published over several years. Prophylaxis with parnaparin has been reported to be more effective than placebo (Valle et al 1988) and more advantageous than UFH. In a series of 140 patients, DVT was detected in legs either by Doppler sonography or ${ }^{125}$ I-fibrinogen uptake test in $7.1 \%$ and $10 \%$ of patients treated, respectively, with parnaparin $3,200 \mathrm{IUaXa} s c(=7,500 \mathrm{aXaU})$ twice daily or calcium UFH 5,000 IU sc 3 times daily, given for 7 days (Chiappuzzo et al 1988). In another trial aimed at preventing post-operative VTE after hip fracture, 49 patients were randomly treated either with parnaparin 3,200 IUaXa twice daily or with UFH $5,000 \mathrm{IU}$ tid. Screening for thrombosis was performed with ${ }^{125}$ I-fibrinogen leg scanning and strain-gauge plethysmography, and positive results were confirmed by venography. In this study, the rate of venographically proven DVT was $20 \%$ in the parnaparin group and $29 \%$ in the UFH group. The difference was not statistically significant since the number of randomized patients was rather small, but there was an interesting trend in favor of parnaparin, as 1 pulmonary embolism and 2 deaths occurred in the UFH group, and none in the parnaparin group (Pini et al 1989).

Bandiera et al (2003) performed a multicenter study on 381 patients at high risk of DVT undergoing major orthopedic surgery; they were treated with UFH, parnaparin or other LMWHs, given around the time of surgery and continued at home for 10-90 days according to the type of operation or risk factors. Parnaparin was administed once daily at doses ranging between 3,200 and 4,250 IUaXa/day. DVT was diagnosed clinically and instrumentally (Echo Color Doppler). The authors concluded that LMWHs were significantly more effective than UFH (DVT rate $10.3 \%$ vs $16.6 \%$ ), and that parnaparin was even slightly more effective (DVT 8.4\%) than other LMWHs, although a significant difference was not achieved (Table 2).

Moreover, while one case of major bleeding was observed for each treatment groups (ie, UFH, parnaparin and other LMWH), episodes of minor bleeding (such as a local hematoma at the site of injection or surgical wound or a need for a surgical drainage) were observed in $17.85 \%, 6.06 \%$, and $11.76 \%$, respectively, of UFH, parnaparin, and other LMWHtreated patients. Other adverse drug reactions (ADRs) 
Table 2 Rate of deep vein thrombosis in patients who underwent surgery for total hip replacment

\begin{tabular}{lll}
\hline & No. patients & No. DVT \\
\hline UFH & 12 & $2(16.67 \%)$ \\
Other LMWHs & 29 & $3(10.34 \%)$ \\
RR ${ }^{\text {va UFH }}$ & & $0.624(0.098-1.148)$ \\
Parnaparin & 59 & $5(8.47 \%)$ \\
RR vs UFH & & $0.463(0.079-2.727)$ \\
RR vs other LMWHs & & $0.832(0.224-1.756)$ \\
\hline
\end{tabular}

${ }^{\mathrm{a}}$ Odds ratios (RR) were calculated with the $95 \%$ confidence limits with reference to UFH (Bandiera et al 2003).

Abbreviations: DVT, deep vein thrombosis; LMWH, low-molecular-weight heparins; UFH, unfractionated heparins.

(such as pain or irritation at the injection site), were observed in $25.0 \%, 7.4 \%$, and $32.4 \%$ of patients treated, respectively, with UFH, parnaparin, and other LMWHs (Table 3).

The slightly higher antithrombotic activity achieved with parnaparin and other LMWHs compared with UFH demonstrates that a higher level of inhibition of $\mathrm{Xa}$ is associated with administration of a LMWH with no increase hemorrhagic risk. Thus, the use of parnaparin appears to be safer in orthopedic prophylaxis, as suggested by Mascali et al (1988), who reported a statistically significant lower incidence of side effects (ie, local hematomas) in parnaparin- than in UFH-treated patients ( $25.0 \%$ vs $64.7 \%)$.

The more appropriate time for starting prophylaxis with parnaparin was investigated by Laguardia and Caroli (1992). Forty patients undergoing THR were randomly treated with parnaparin 6,400 IUaXa in once-daily administration starting either 2 hours before or 2 hours after the surgical operation. The treatment lasted 7 days. The results showed that the incidence of DVT was very similar and extremely low in the two groups, only 1 patient in each group having a positive diagnosis on phlebography. Although the sample size was relatively small, the authors concluded that prophylaxis was effective in both groups with a DVT rate approaching $5 \%$, and without any significant difference between groups in the amount of perioperative bleeding.

Table 3 Rate of major and minor bleeding and other adverse drug reactions (ADR) observed with unfractionated heparins, parnaparin and other low-molecular-weight heparins (Bandiera et al 2003)

\begin{tabular}{lllll}
\hline & $\begin{array}{l}\text { No. } \\
\text { patients }\end{array}$ & $\begin{array}{l}\text { No. major } \\
\text { bleedings }\end{array}$ & $\begin{array}{l}\text { No. minor } \\
\text { bleedings }\end{array}$ & $\begin{array}{l}\text { No. other } \\
\text { ADRS }\end{array}$ \\
\hline UFH & 28 & $\mathrm{I}(3.57 \%)$ & $5(17.85 \%)$ & $7(25.00 \%)$ \\
Parnaparin & $23 \mathrm{I}$ & $\mathrm{I}(0.43 \%)$ & $14(6.06 \%)$ & $17(7.36 \%)$ \\
Other LMWHs & 102 & $\mathrm{I}(0.98 \%)$ & $12(11.76 \%)$ & $33(32.35 \%)$ \\
\hline
\end{tabular}

Abbreviations: ADRS, artificial disc replacement surgery; LMWH, lowmolecular-weight heparins; UFH, unfractionated heparins.

\section{Parnaparin in minor orthopedic surgery}

Over the past 20 years, arthroscopy has become an important tool in orthopedics for virtually every joint. Complication rates for arthroscopy are low but not absent $(<8.2 \%)$, including DVT and PE, whose incidence may be increased either by specific risk factors of patients (such as old age, obesity, and concomitant venous diseases) or by the local ischemia secondary to the use of a tourniquet (Table 4). Thus, the need for prophylaxis in minor orthopedic surgery should not be undervalued (Poulsen et al 1993; Eynon et al 2004; Navarro-Sanz and Fernandez-Ortega 2004).

Clinical studies show that adequate prophylaxis can be achieved with LMWHs (Table 5).

In order to obtain information about the efficacy and safety of parnaparin in minor orthopedic surgery under tourniquet ischemia, we have identified prospectively 509 patients in our center. Knee arthroscopy represented the most frequent surgery ( $68 \%$ of the survey), followed by removal of a fixation device or other foreign material (14\%), foot surgery (8.1\%), arthroscopy of the ankle and shoulder (1.6\%), biopsy (5.1\%), and other surgery (3.3\%).

The antithromboembolic prophylaxis with once-daily parnaparin (3,200-4,250 IUaXa) was initiated within 6 hours after the end of surgery and extended until full weight bearing and walking was resumed (10.5 \pm 9.1 days). All the patients underwent compression ultrasound on days 8 to 10 or with the onset of clinical signs suggesting DVT. Instrumental tests never revealed proximal DVT, while minor bleeding (hematoma in surgical site with hemoglobin decrease $<2 \mathrm{~g} / \mathrm{dL}$ ) was found in 7 cases (1.4\%) (Montebugnoli et al 2007).

\section{Other uses of parnaparin}

Parnaparin has been also employed for TVE prophylaxis in non-orthopedic surgery. A multicenter study performed by Verardi et al (1988) on 610 patients undergoing general (mainly abdominal) surgery, a statistically significant difference was observed between parnaparin 3,200-6,400 IUaXa once daily and UFH in the rate of post-operative DVT (3.2\% vs $6.3 \% ; \mathrm{p}<0.01$ ), although the difference in the incidence of PE between treatment groups did not reach significance (0.3 vs $1.0 \%)$.

Parnaparin has been used for VTE prophylaxis in bariatric surgery. Ten severely obese patients (body mass index $>50 \mathrm{~kg} / \mathrm{m}^{2}$ ) have been treated with increasing single daily doses of parnaparin $(3,200,4,250$, and $6,400 \mathrm{IUaXa})$ on the three consecutive days leading up to biliointestinal bypass surgery. The highest dose was continued from the day of surgery until day 30 (recovery period). During the pre-operative 
Table 4 Prospective uncontrolled trials, without heparin prophylaxis, in knee arthroscopy using objective methods for detecting deep vein thrombosis

\begin{tabular}{|c|c|c|c|c|}
\hline Study & No. patients & Diagnosis method & & s thrombosis (no. $/ \%$ \\
\hline Stringer et al (1989) & 48 & Venography & 2 & $4.2 \%$ \\
\hline Williams et al (1995) & 85 & Compression ultrasonography & 3 & $3.5 \%$ \\
\hline Cullison et al (1996) & 67 & Compression ultrasonography & 1 & $1.5 \%$ \\
\hline Durica et al (1997) & 190 & Venography & 6 & $3.2 \%$ \\
\hline Demers et al (1998) & 184 & Venography & 33 & $17.9 \%$ \\
\hline Jaureguito et al (1999) & 239 & Venography & 7 & $2.9 \%$ \\
\hline Wirth et al (200I) & 117 & Venography & 5 & $4.3 \%$ \\
\hline Delis et al (200I) & 102 & Color Duplex & 8 & $7.41 \%$ \\
\hline Total & 1,032 & & 65 & $6.29 \%$ \\
\hline
\end{tabular}

Adapted with permission from Wirth T, Schneider B, Misselwitz F, et al. 200I. Prevention of venous thromboembolism after knee arthroscopy with low-molecular weight heparin (reviparin): results of a randomized, controlled trial. Arthroscopy, 17:393-9. Copyright ( $)$ Elsevier Ltd, and reproduced with permission from Montebugnoli M, Bugamelli S, Zangheri E, et al. 2007. Prophylaxis of venous thromboembolism in minor orthopedic surgery with parnaparin. Clin Appl Thromb Hemost, I3:249-58. Copyright @ Sage publications.

dosing phase, parnaparin dose-dependently prolonged APTT, with the 6,400 IUaXa dose significantly prolonging aPTT vs the lower doses. Meanwhile, the 4,250 and 6,400 IUaXa once-daily doses increased anti-factor Xa and anti-factor IIa activity. After surgery, 1 patient with heparin resistance experienced pulmonary embolization. No bleeding complications were observed. The dose-response data reported in this preliminary study suggest that parnaparin doses of 4,250 and 6,400 IUaXa may provide effective prophylaxis for VTE in patients undergoing bariatric surgery. However, given the small number of patients, larger, well-controlled trials are required to confirm these findings (Forestieri et al 2007).

Bellosta et al (2007) have compared the effectiveness of nadroparin and parnaparin in the non-prophylactic treatment of DVT in terms of the evolution of thrombosis, in a randomized prospective study in 91 patients. Overall, there were 3 cases $(3.3 \%)$ of progression of thrombosis despite therapy with LMWH, 2 cases (5\%) in the nadroparin group, and 1 case $(2 \%)$ in the parnaparin group (not significant). The Doppler ultrasound in the follow-up showed a complete resolution of $56 \%$ of DVT at an average of $6.1 \pm 4.6$ months.
Valve competence recovered in $65.9 \%$ of cases with no significant difference between the two groups.

Parnaparin has been successfully used in the treatment of coronary artery diseases (CAD). Parnaparin 6,400 IUaXa once daily sc for 7 days was more effective than UFH given intravenously for 48 hours, then sc (UFH 5,000 IU every 6 hours) for 5 days in a randomized, multicenter study in patients $(n=897)$ with unstable angina. The incidence of the triple composite endpoint (death, acute myocardial infarction $[\mathrm{MI}]$ or the need for myocardial revascularizations in the 7 days after the start of treatment) was significantly lower in the parnaparin than in the UFH group ( $7 \%$ vs $11 \%$; $\mathrm{p}=0.034)$ (Prime Care Study 2005).

Similarly, in patients with an acute STEMI, sc parnaparin 4,250 IUaXa every 12 hours for 7 days was associated with a lower incidence of a triple composite endpoint of death, acute MI, or the need for myocardial revascularization in the 45 days after the start of treatment than intravenous UFH administered for 3 days followed by subcutaneous UFH 7,500 IU every 12 hours for 4 days ( $27 \%$ vs $42 \%$; $\mathrm{p}=0.03$ ) (Wang et al 2006). Moreover, in patients with stable

Table 5 Rate of deep vein thrombosis in patients undergoing knee arthroscopy and receiving different low-molecular-weight heparin prophylactic treatment (revision of the literature)

\begin{tabular}{llllll}
\hline LMWH & Dose (IU/die) & Study & No. patients & Diagnostic method & DVT rate (No./\%) \\
\hline Reviparin & 1,750 & Wirth et al (200I) & II6 & Eco-color Doppler & I/0.86\% \\
Dalteparin & $2,500-5,000$ & Michot et al (2002) & 66 & Compression ultrasound & $\mathrm{I} / \mathrm{I} .52 \%$ \\
Dalteparin & 5,000 & Schippinger et al (1998) & $10 \mathrm{I}$ & Duplex ultrasound & $12 / \mathrm{II} .88 \%$ \\
Nandroparin & 3,075 & Holland and Schain (1995) & $10 \mathrm{I}$ & Unknown & $5 / 4.95 \%$ \\
Parnaparin & $3,200-4,250$ & Montebugnoli et al (2007) & 509 & Compression ultrasound & $0 / 0.00 \%$ \\
\hline
\end{tabular}

Abbreviations: DVT, deep vein thrombosis; LMWH, low-molecular-weight heparins; UFH, unfractionated heparins. 
angina, parnaparin 6,400 IUaXa once daily, together with conventional therapy, significantly increased exercise time compared with placebo (Melandri et al 1993).

Finally, in patients with peripheral arterial obstructive disease a long-term treatment (6-8 months) with parnaparin 6,400 IUaXa once daily sc significantly improved the pain-free walking time/distance compared with baseline in several studies (Palmieri et al 1988; Mannarino et al 1991; Calabro et al 1993; Simoni et al 1993). The extent of improvement with parnaparin was similar to that demonstrated with UFH in one study (Di Stefano et al 1988).

\section{Tolerability of parnaparin}

In humans, a higher rate of post-operative bleeding has been observed to related closely to the dose administered: at a prophylactic dose (3,200-6,400 IUaXa/day) the risk of bleeding is statistically not significant, and in any case lower than that observed with UFH (Martines et al 1990; Bandiera et al 2003). LMWHs do not cross the human placenta and are not detected in fetal blood during the first 6 months of pregnancy (Forestier et al 1984; Ostergaard et al 1989); therefore, they are also safe in pregnant women (Geerts et al 2004; Desai and Suk 2007). Although rare episodes of immunomediated thrombocytopenia due to the use of other LMWHs have been reported (Lecompte et al 1991; Mohr and Lenz 1991), thrombocytopenia related to the use of parnaparin has not yet been observed.

At a local level, the tolerability of parnaparin seems better than that of UFH, with a lower rate of hematomas, pain, and burning in the injection site (Corrado et al 1989; Verardi et al 1989; Mangialardi et al 1991; Della Marchina et al 1993; Bandiera et al 2003; Bellosta et al 2007).

\section{Conclusions}

A review of the literature shows that parnaparin, like other LMWHs, is effective and well tolerated when used for prophylaxis of post-operative VTE in orthopedic surgery. Its effectiveness seems to be far superior to that of UFH, and comparable with other LMWHs when initiated pre- or post-operatively near the time of surgery and continued at home for a period depending on the type of operation. Besides the clinical advantages, parnaparin and other LMWHs enable a simpler home management of the prophylaxis since they can be administered once a day and do not require continuous lab tests.

\section{Disclosures}

The authors report no conflicts of interest.

\section{References}

Antiplatelet Trialists' Collaboration. 1994. Collaborative overview of randomised trials of antiplatelet therapy III: reduction in venous thrombosis and pulmonary embolism by antiplatelet prophylaxis among surgical and medical patients. BMJ, 308:235-46.

Arcelus JI, Kudrna JC, Caprini JA. 2006. Venous thromboembolism following major orthopedic surgery: what is the risk after discharge? Orthopedics, 29:506-16.

Bandiera S, Casalini D, Friemel P, et al. 2003. Clinical experience with parnaparin in orthopedic sugery. Eur Bull Drug Res, 11:77-91.

Bellosta R, Ferrari P, Luzzani L, et al. 2007. Home therapy with LMWH in deep vein thrombosis: randomized study comparing single and double daily administrations. Angiology, 58:316-22.

Calabro A, Piarulli F, Milan D, et al. 1993. Clinical assessment of low molecular weight heparin effects in peripheral vascular disease. Angiology, 44:188-95.

Chiapuzzo E, Orengo GB, Ottrida G, et al. 1988. The use of low molecular weight heparins for postsugical deep vein thrombosis prevention in orthopedic patients. J Int Med Res, 16:359-66.

Collins R, Scrimgeour A, Yusuf S, et al. 1988. Reduction in fatal pulmonary embolism and venous thrombosis by perioperative administration of subcutaneous heparin. Overview of results of randomized trials in general, orthopedic, and urologic surgery. $N$ Engl $J$ Med, 318:1162-73.

Colwell CW Jr, Spiro TE, Trowbridge AA, et al. 1994. Use of enoxaparin, a low-molecular-weight heparin, and unfractionated heparin for the prevention of deep venous thrombosis after elective hip replacement. A clinical trial comparing efficacy and safety. J Bone Joint Surg Am, 76:3-14.

Corrado F, Fini M, Severini G, et al. 1989. Low molecular weight heparin (Fluxum) prevention of post-operative thrombosis in urological surgery: a controlled study. Clin Trials J, 26:138-48.

Cullison TR, Muldoon MP, Gorman JD, et al. 1996. The incidence of deep venous thrombosis in anterior cruciate ligament reconstruction. Arthroscopy, 12:657-9.

Deasai P, Suk M. 2007. Orthopedic trauma in pregnancy. Am J Orthop, 36: E160-6.

Delis KT, Hunt N, Strachan RK, et al. 2001. Incidence, natural history and risk factors of deep vein thrombosis in elective knee arthroscopy. Thromb Haemost, 86:817-21.

Della Marchina M, Renzi G, Renzi C, et al. 1993. Low molecular weight heparins in chronic venous insufficiency: controlled trial of parnaparin efficacy and tolerability. Brit J Clin Res, 4:29-36.

Demers C, Marcoux S, Ginsberg JS, et al. 1998. Incidence of venographically proved deep vein thrombosis after knee arthroscopy. Arch Intern Med, 158:47-50.

Di Stefano F, Giglio A, Vinci M, et al. 1988. Low molecular weight heparins prevention of post-operative deep vein thrombosis in vascular surgery. Pharmatherapeutica, 5:261-5.

Durica SS. 1997. Venous thromboembolism in the cancer patient. Curr Opin Hematol, 4:306-11.

Eynon AM, James S, Leach P. 2004. Thromboembolic events after arthroscopic knee surgery. Arthroscopy, 20(Suppl 2):23-34.

Fitzgerald RH Jr, Spiro TE, Trowbridge AA, et al. 2001. Prevention of venous thromboembolic disease following primary total knee arthroplasty. A erandomized, multicenter, open-label, parallel-group comparison of enoxaparin and warfarin. J Bone Joint Surg Am, 83A:900-6.

Forestier F, Daffos F, Capella-Pavlovsky M. 1984. Low molecular weight heparin (PK10169) does not cross the placenta during the second trimester of pregnancy: study by direct fetal blood sampling under ultrasound. Thromb Res, 34:557-60.

Forestieri P, Quarto G, De Caterina M, et al. 2007. Prophylaxis of thromboembolism in bariatric surgery with parnaparin. Obes Surg, 17:1558-62.

Freedman KB, Brookenthal KR, Fitzgerald RH Jr, et al. 2000. A meta-analysis of thromboembolic prophylaxis following elective total hip arthroplasty. J Bone Joint Surg Am, 82-A:929-38. 
Geerts WH, Heit JA, Clagett P, et al. 2001. Prevention of venous thromboembolism. Chest, 119:S132-S75.

Geerts WH, Pineo GF, Heit JA, et al. 2004. Prevention of venous thromboembolism: the seventh ACCP conference on antithrombotic and thromblytic therapy. Chest, 126:338S-400S.

German Hip Arthroplasty Trial (GHAT) Group. 1992. Prevention of deep vein thrombosis with low molecular weight heparin in patients undergoing total hip replacement. A randomized trial. Arch Orthop Trauma Surg, 111:110-20.

Goldhaber SZ. 2004. Pulmonary embolism. Lancet, 363:1295-305.

Haas S, Breyer HG, Bacher HP, et al. 2006. Prevention of major venous thromboembolism following total hip or knee replacement: a randomized comparison of low-molecular weight heparin with unfractioned heparin (ECHOS Trial). Int Angiol, 25:335-42.

Holland K, Schain FH. 1995. Prevention of thrombosis with fraxiparin 0.3 after arthroscopic interventions. Fortschr Med, 113:335-6.

Hull RD, Pineo GF, Francis C, et al. 2000. Low-molecular-weight heparin prophylaxis using dalteparin in close proximity to surgery vs warfarin in hup arthroplasty patients: a double-blind, randomized comparison Arch Intern Med, 160:2199-207.

Hull RD, Pineo GF, Stein PD, et al. 2001. Timing of initial administration of low molecular weight heparin prophylaxis against deep vein thrombosis in patients following elective hip arthroplasty: a Systematic review. Arch Int Med, 161:1952-60.

Imperiale TF, Speroff T. 1994. A meta-analysis of methods to prevent venous thromboembolism following total hip replacement. JAMA, $271: 1780-5$

Juareguito JW, Greenwald AE, Wilcox JF, et al. 1999. The incdence of deep venous thrombosis after arthroscopic knee surgery. Am J Sports Med 27: 707-10.

Koch A, Ziegler S, Breitschwerdt H, et al. 2001. Low molecular weight heparin and unfractionated heparin in thrombosis prophylaxis: meta-analysis based on original patient data. Thromb Res, 102:295-309.

Laguardia AM, Caroli GC. 1992. Prevention of deep vein thrombosis in orthopaedic surgery. Comparison of two different treatment protocols with low molecular weight heparin (Fluxum). Curr Med Res Opin, 12:584-93.

Lecompte T, Luo SK, Stieltjes N, et al. 1991. Correspondence. Lancet, 338:1217.

Ludwig RJ, Alban S, Bistrian R, et al. 2006. The ability of different forms of heparins to suppress $\mathrm{P}$-selectin function in vitro correlates to their inhibitory capacity on blood borne metastasis in vivo. Throm Haemost, 95:535-40.

Mangialardi N, Matteoni R, Serrao E, et al. 1991. Medium term treatment of thrombotic pathologies of the lower limbs with a new LMW heparin Med Prax, 12:1-7.

Mannarino E, Pasqualini L, Innocente S, et al. 1991. Efficacy of lowmolecular-weight heparin in the management of intermittent claudication. Angiology, 42: 1-7.

Martines G, Restori G. 1990. Estimation of the dose-effect relationship of a low molecular weight heparin (Fluxum) through meta-analysis of clinical data. Int Rev Clin Sci, 2:79-90.

Mascali F, Condorelli A, Salanitri G, et al. 1988. Post-surgery thromboembolism prevention by LMW heparin subcutaneous administration. Eur Rev Med Pharmacol Sci, 10:135-41.

Maugeri N, De Gaetano G, Barbanti M, et al. 2005. Prevention of platelet-polymorphonuclear leukocyte interactions: new clues to the antithrombotic properties of parnaparin, a low molecular weight heparin. Haematologica, 90:833-9.

Maugeri N, Di Fabio G, Barbanti M, et al. 2007. Parnaparin, a low-molecularweight heparin, prevents P-selectin-dependent formation of platelet-leukocyte aggregates in human whole blood. Thromb Haemost, 97:965-73.

McKeage K, Keating GM. 2008. Parnaparin: a review of its use in the management of venous thromboembolism, chronic venous disease and other vascular disorders. Drugs, 68:105-22.

Melandri G, Semprini F, Cervi V, et al. 1993. Benefit of adding low molecular weight heparin tot he conventional treatment of stable angina pectoris: a double-blind, randomized, placebo-controlled trial. Circulation, 88:2517-23.
Michot M, Conen D, Holtz D, et al. 2002. Prevention of deep-vein thrombosis in ambulatory arthroscopic knee surgery: a randomized trial of prophylaxix with low-molecular weight heparin. Arthroscopy, 18:257-63.

Milani MR, Palazzini E. 1990. Neutralization of fluxum, a low molecular weight heparin, by protamine. Int Rev Med Sc, 2:45-9.

Mohr VD, Lenz J. 1991. Heparin-assoziierte thrombocytopenie, thrombose und embolie. Unerwunschte wirkung der thromboembolieprophylaxe mit dem niedermolekularen heparin enoxaparin. Chirurg, 62: 686-90.

Montebugnoli M, Bugamelli S, Zangheri E, et al. 2007. Prophylaxis of venous thromboembolism in minor orthopedic surgery with parnaparin. Clin Appl Thromb Hemost, 13:249-58.

Navarro-Sanz A, Fernandez-Ortega JF. 2004. Fatal pulmonary embolism after knee arthroscopy. Am J Sports Med, 32:525-8.

Nurmohamed MT, Rosendaal FR, Buller HR, et al. 1992. Low-molecular weight heparin versus standard heparin in general and orthopaedic surgery: a meta-analysis. Lancet, 340:152-6.

Obermosterer A, Schippinger G, Lipp RW, et al. 1999. Thromboembolic events following arthroscopic knee sugery. JAMA, 282:431.

Ostergaard P, Matzsch T, Bergqvist D, et al. 1989. Trans placental passage of a low molecular weight heparin as compared to standard heparin. Tromb Haem, 62:515.

Palmer AJ, Koppenhagen K, Kirchhof B, et al. 1997. Efficacy and safety of low molecular weight heparin, unfractioned heparin and warfarin for thrombo-embolism prophylaxis in orthopaedic surgery: a meta-analysis of randomized clinical trials. Haemostasis, 27:75-84.

Pini M, Tagliaferri A, Manotti C, et al. 1989. Low molecular weight heparin (Alfa LMWH) compared with unfractionated heparin in prevention of deep-vein thrombosis after hip fractures. Int Angiol, 8:134-9.

Planes A, Vochelle N, Mazas F, et al. 1988. Prevention of postoperative venous thrombosis: a randomized trial comparing unfractionated heparin with low molecular weight heparin in patients undergoing total hip replacement. Thromb Haemost, 60:407- 10.

Poulsen KA, Borris LC, Lassen MR. 1993. Thromboembolic complications after arthroscopy of the knee. Arthroscopy, 9:570-3.

Prime Care Study Investigators Group. 2005. Comparative efficacy of once daily parnaparin and unfractionated heparin in unstable angina pectoris: PRIME CARE study. Indian Heart J, 57: 648-54.

Prejbeanu R, Vermesan H, Dragulescu SI, et al. 2007. Thromboembolic risk after knee endoprosthesis. Eur Rev Med Pharmacol Sci, 11:297-300.

Raskob GE, Hirsh J. 2003. Controversies in timing of the first doses of anticoagulant prophylaxis against thromboembolism after major orthopaedic surgery. Chest, 124:379S-85S

Samama CM, Vray M, Barrè J, et al. 2002. Exteded venous thromboembolism prophylaxix after total hip replacement: a comparison of lowmolecular weight heparin with oral anticoagulant. Arch Intern Med, 162:2191-6.

Schippinger G, Wirnsberger GH, Obernosterer A, Babinski K. 1998. Thromboembolic complications after arthroscopic knee surgery. Incidence and risk factors in 101 patients. Acta Orthop Scand, 69:144-6.

Simoni G, Lucertini G, Decian F. 1993. Low molecular weight heparins: therapeutic insight in peripheral arterial occlusive disease. Clin Trials Metaanal, 28:137-45.

Strebel N, Prins M, Agnelli G, et al. 2002. Preoperative or postoperative start of prophylaxis for venous thromboebolism with low-molecular weight heparin in elective hip sugery? Arch Int Med, 162:1451-6.

Stringer MD, Steadman CA, Hedges AR, et al. 1989. Deep vein thrombosis after elective knee surgery. An incidence study in 312 patients. $J$ Bone Joint Surg Br, 71:492-7.

Valle I, Sola G, Origone A. 1988. Controlled clinical study of the efficacy of a new low molecular weight heparin administered subcutaneously to prevent postoperative deep venous thrombosis. Curr Med Res Opin, 11:80-6.

Verardi S, Casciani CU, Nicora E, et al. 1988. A multicentre study on LMW-heparin effectiveness in preventing postsurgical thrombosis. Int Angiol, 7:19-24. 
Verardi S, Cortese F, Baroni B, et al. 1989. Deep vein thombosis prevention in surgical patients: effectiveness and safety of a new low molecular weight heparin. Curr Ther Res, 46:366-72.

Verhaege R. 2005. Extended prophylaxis of venous thrombolism in major orthopaedic surgery. Acta Orthop Belg, 71:255-9.

Wang X-K, Zhang Y, Yang C-M, et al. 2006. Use of unfractionated heparin and a low-molecular-weight heparin following thrombolytic therapy for acute ST-segment elevation myocardial infarction. Clin Drug Invest, 26:341-9.

White RH, Romano PS, Zhou H, et al. 1998. Incidence and time of thromboembolic outcomes following hip or knee arthroplasty. Arch Intern Med, 158:1525-31.
Williams JS Jr, Hulstyn MJ, Fadale PD, et al. 1995. Incidence of deep vein thrombosis after arthroscopic knee surgery: a prospective study. Arthroscopy, 11: 701-5.

Wirth T, Schneider B, Misselwitz F, et al. 2001. Prevention of venous thromboembolism after knee arthroscopy with low-molecular weight heparin (reviparin): results of a randomized, controlled trial. Arthroscopy, 17:393-9. 